\title{
Surface Functionality Features of Nanosized Silica Obtained by Electron Beam Evaporation at Ambient Pressure
}

\author{
S. P. Bardakhanov, ${ }^{1}$ I. V. Vasiljeva, ${ }^{2}$ N. K. Kuksanov, ${ }^{3}$ and S. V. Mjakin ${ }^{2}$ \\ ${ }^{1}$ Khristianovich Institute of Theoretical and Applied Mechanics of the Siberian Division of the Russian Academy of Sciences, \\ 4/1 Institutskaya Street, Novosibirsk 630090, Russia \\ ${ }^{2}$ Engineering Technology Center RADIANT, Ltd., 50 Dibunovskaya Street, St-Petersburg 197183, Russia \\ ${ }^{3}$ Budker Institute of Nuclear Physics of the Siberian Division of the Russian Academy of Sciences, 11 Prospect Akademika Lavrentieva, \\ Novosibirsk 630090, Russia
}

Correspondence should be addressed to I. V. Vasiljeva, radiant@skylink.spb.ru

Received 5 March 2010; Accepted 13 May 2010

Academic Editor: Sridhar Komarneni

Copyright ( 2010 S. P. Bardakhanov et al. This is an open access article distributed under the Creative Commons Attribution License, which permits unrestricted use, distribution, and reproduction in any medium, provided the original work is properly cited.

A series of nanosized silica powders with different specific surface values are synthesized by electron beam evaporation in air at ambient pressure. The obtained silica samples are featured with relatively low apparent density and high content of oxygen and hydroxyl groups on the surface making these materials promising for specific applications.

\section{Introduction}

Nanosized powdered silica such as Aerosil is a promising class of inorganic materials useful in various application areas. Although their properties are generally studied in detail [1], each specific type of silica is characterized by unique performances determined by peculiarities of the process used for its synthesis. The characteristics of nanosized particles and properties of their highly developed surface including the content of various functional groups are among the most significant factors responsible for the efficiency of such powdered materials in certain applications. Particularly, structural features of the surface layer and the content of siloxane and silanol groups with different acid-base properties (determined by their spatial environment and electron density distribution) are among the main factors responsible for silica reactivity. Therefore, the search for approaches to obtaining particles with controllable surface composition, functionality, and properties in combination with the development of methods for precise characterization of structural and electronic features of surface functional groups is one of the challenges for modern technologies involving silica application.
This article reports the synthesis of nanosized powdered silica with controllable bulk and surface properties by electron beam evaporation and characterization of their features depending on the process conditions.

\section{Experimental}

Powdered silica samples developed under Tarkosil brand were synthesized by electron beam evaporation using a commercial electron accelerator ELV-6 produced by Budker Institute of Nuclear Physics of the Siberian Branch of the Russian Academy of Sciences. The accelerator provides the power up to $100 \mathrm{~kW}$, electron beam energy as high as 1.4 MeV, and relativistic rates of electrons in air with the "free path length" up to $6 \mathrm{~m}$. The power density up to $5 \mathrm{MW} / \mathrm{cm}^{2}$ affords the evaporation of refractory compounds at ambient conditions and performance of various syntheses at high temperature gas environment. The advantages of electron beam-initiated processes also include a high efficiency due to the direct conversion of electric power into heating of the processed material with the rate above $1000^{\circ} \mathrm{C} / \mathrm{s}$ and absence of any chemical reagents. 
In the considered synthesis described in detail in [25], this electron accelerator operating at $70 \mathrm{~kW}$ was used to evaporate quartz sand of $99.6 \%$ purity in the reactor. The resulting vapor was evacuated from the heating area and cooled by mixing with air followed by the condensation and isolation of silica nanoparticles. Silica powders were obtained with the yield $6-7 \mathrm{~kg} /$ hour. The variation of the process parameters including the power density per unit of the evaporated material surface as well as the cooling air humidity and flow rate allowed us to obtain powders with adjustable properties.

The samples selected for surface characterization in this study were featured with different specific surface values, that is, $59,100,140$, and $150 \mathrm{~m}^{2} / \mathrm{g}$ measured by four-point BET method with nitrogen adsorption using a Sorbi-M installation produced by META Co.

For comparison, commercial aerosils produced by Degussa (Germany) under the trade brands A-90 and A380 with the specific surface areas correspondingly 90 and $380 \mathrm{~m}^{2} / \mathrm{g}$ were also studied.

The surface functionality of the samples was studied using the adsorption of acid-base indicators with different intrinsic $\mathrm{p} K_{\mathrm{a}}$ values in the range $-5 \cdots 15$ undergoing a selective adsorption on the surface sites with the corresponding $\mathrm{p} K_{\mathrm{a}}$ values. This method described in detail in [6-8] is based on spectrophotometric measurement of optical densities $(D)$ for standard aqueous solutions of such indicators at wavelengths corresponding to their light absorption maximums in the following conditions:

(i) for the initial indicator solution as a blank test $\left(D_{0}\right)$,

(ii) for a similar solution after dipping of a $\sim 20 \mathrm{mg}$ sample of the studied material to determine the optical density $D_{1}$. This value differs from $D_{0}$ as a result of two factors: (1) partial adsorption of the indicator and (2) change in water acidity due to the material-water interaction,

(iii) for the indicator solution added to distilled water decanted after the contact with a similar sample of the studied material. This measurement gives the optical density $D_{2}$ differing from $D_{0}$ only due to water acidity change as a result of water-material interaction. This effect of this factor is eliminated by calculating the content of active sites with the corresponding $\mathrm{p} K_{\mathrm{a}}$ value as

$$
q\left(\mathrm{p} K_{\mathrm{a}}\right)=\left|\frac{\left|D_{0}-D_{1}\right|}{m_{1}} \pm \frac{\left|D_{0}-D_{2}\right|}{m_{2}}\right| \cdot C_{\text {ind }} \cdot \frac{V_{\text {ind }}}{D_{0}},
$$

where $C_{\text {ind }}$ is the indicator concentration in the initial solution, $V_{\text {ind }}$ is the indicator solution volume used for the analysis, $m_{1} \approx m_{2}=20.0 \pm \sim 0.5 \mathrm{mg}$ are the weights of the samples used for measuring $D_{1}$ and $D_{2}$ accordingly, "+" sign corresponds to the opposite changes of $D_{1}$ and $D_{2}$ relating to $D_{0}$, and "-" sign is used in the case both $D_{1}$ and $D_{2}$ are either greater or less than $D_{0}$.

The intrinsic $\mathrm{p} K_{\mathrm{a}}$ values of the acid-base indicators and wavelengths corresponding to their absorption maximums are shown in Table 1.
TABLE 1: Acid-base indicators and their parameters.

\begin{tabular}{lcc}
\hline Indicator & $\mathrm{p} K_{\mathrm{a}}$ & Wavelength $\lambda, \mathrm{nm}$ \\
\hline Ethylene glycol & 14.2 & 200 \\
Indigo-carmine & 12.8 & 610 \\
Nile blue & 10.5 & 640 \\
Tymol blue & 8.8 & 430 \\
Bromo-tymol blue & 7.3 & 430 \\
Bromo-crezyl purple & 6.4 & 590 \\
Methyl red & 5.0 & 430 \\
Bromo-phenol blue & 4.1 & 590 \\
Methyl orange & 3.5 & 460 \\
m-nitroaniline & 2.5 & 340 \\
Fuccine & 2.1 & 540 \\
Brilliant green & 1.3 & 610 \\
Crystalline violet & 0.8 & 580 \\
o-nitroaniline & -0.3 & 410 \\
p-chloro-nitroaniline & -0.9 & 330 \\
Dinitroaniline & -4.4 & 340 \\
\hline
\end{tabular}

The content of single hydroxyl groups on the surface of the silica samples was also estimated by IR spectroscopy according to the preliminarily calibrated intensity of absorption band at $3750 \mathrm{~cm}^{-1}$ using FTIR spectrometer Shimadzu 8300 .

The apparent density of the studied materials was measured gravimetrically using a standard cell.

\section{Results and Discussion}

The distribution of adsorption sites on the surface of the studied nanosized silica particles as a function of their $\mathrm{p} K_{\mathrm{a}}$ values is shown in Figure 1.

These data generally indicate the presence of different types of adsorption centers on the surface of the considered materials including Lewis basic $\left(\mathrm{p} K_{\mathrm{a}}<\sim 0\right.$, formed by oxygen atoms) and acidic ( $\mathrm{p} K_{\mathrm{a}}>\sim 14$, formed by silicon atoms) as well as Brensted acidic $\left(\mathrm{p} K_{\mathrm{a}} \sim 0 \cdots 6\right)$, neutral $\left(\mathrm{p} K_{\mathrm{a}} \sim 6 \cdots 8\right)$, and basic $\left(\mathrm{p} K_{\mathrm{a}} \sim 8 \cdots 14\right)$ centers corresponding to hydroxyl groups.

The overall content of adsorption sites drops with the increase of the specific surface to the minimum at $140 \mathrm{~m}^{2} / \mathrm{g}$ followed by a certain increase with the further growth of $S$ up to $150 \mathrm{~m}^{2} / \mathrm{g}$ and an abrupt decrease in the case of Aerosil A-380 (Figure 2).

This trend generally correlates with the changes in the apparent density for these samples summarized in Table 2.

The decrease of both apparent density (indicating the increase in the size of the particles or their agglomerates) and the content of functional groups on the surface with the increase of the specific surface suggests that specific surface grows due to the increased particle porosity or larger spaces between the particle associates determined by their size and shape. These ultrapores and spaces available for the gaseous adsorbate used for $S$ measurements are not available for large molecules of acid-base indicators used for the analysis of 
TABLe 2: Apparent density of the studied materials.

\begin{tabular}{|c|c|c|c|c|c|c|}
\hline \multirow{2}{*}{$\frac{\text { Materials }}{S, \mathrm{~m}^{2} / \mathrm{g}}$} & \multicolumn{4}{|c|}{ Nanosized silica particles synthesized by electron beam evaporation } & \multicolumn{2}{|c|}{ Aerosils produced by Degussa } \\
\hline & 59 & 100 & 140 & 150 & 90 & 380 \\
\hline$\rho_{\text {app }}, \mathrm{mg} / \mathrm{cm}^{3}$ & 81.1 & 47.6 & 37.2 & 38.4 & 25.6 & 32.3 \\
\hline
\end{tabular}

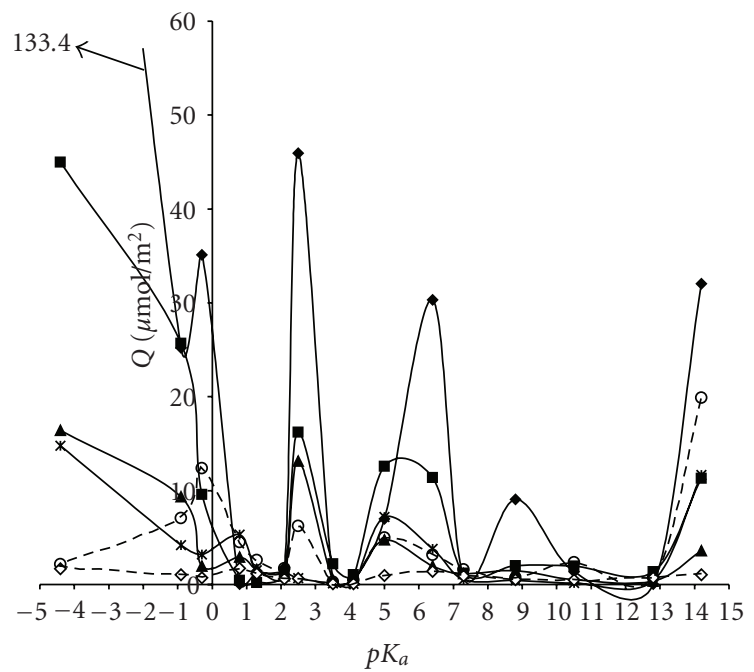

Figure 1: Distribution of adsorption centers as a function of their $\mathrm{p} K_{\mathrm{a}}$ values on the surface of electron beam evaporated silica samples with the specific surface areas $S=59(\bullet \bullet), 100(\neg-), 140(\neg-)$

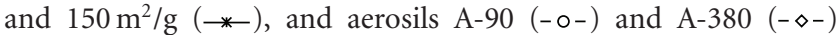
produced by Degussa Co.

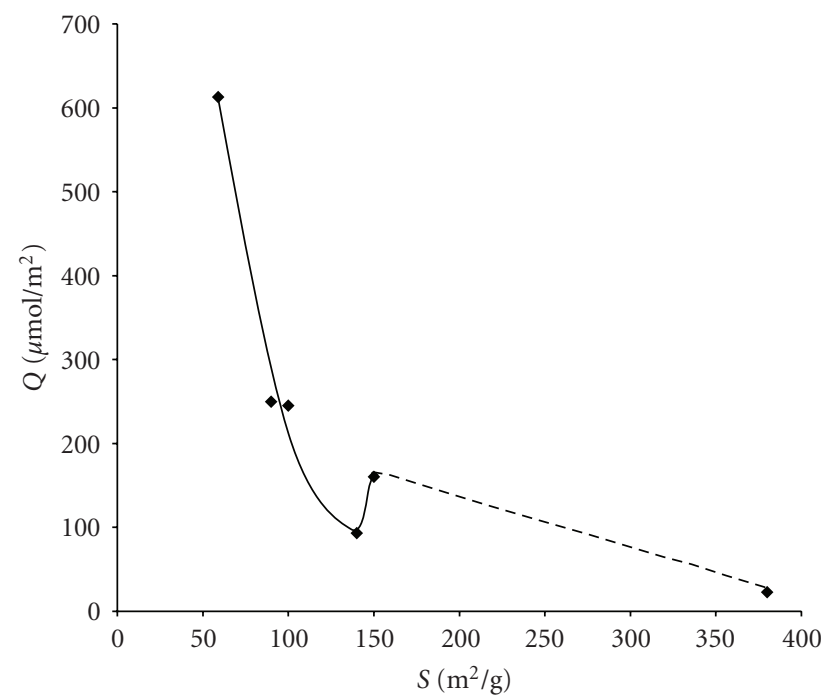

FIGURE 2: Overall content of adsorption centers on the surface of the studied samples as a function of their specific surface area.

adsorption sites. The overall "porosity" of the synthesized materials reaches the maximum at $S=140 \mathrm{~m}^{2} / \mathrm{g}$.

The apparent density of the Degussa Aerosils falls out of the general trend (for A-90) and grows with the increase of their specific surface that indicates the essential difference of their structure from that of the nanosized silica synthesized by electron beam evaporation. The drastic decrease in the content of adsorption centers for the Aerosil A-380 (Figure 2) is probably determined by a small size of its particles $(\sim 7 \mathrm{~nm})$ limiting the access of indicator molecules to active sites on its surface. Another possible factor responsible for this effect is the formation of hydrogen bonds between the particles significantly reducing the amount of available adsorption centers.

A similar profile as a function of the specific surface with a prominent minimum at $140 \mathrm{~m}^{2} / \mathrm{g}$ is also observed for the content of some adsorption sites intrinsic to silica nanoparticles, particularly for the centers with $\mathrm{p} K_{\mathrm{a}}-0.3$ (corresponding to silicon atoms in siloxane groups $[1,6]$ ), 5 (usually weak Brensted acids formed by hydroxyls connected with hydrogen bonds), 6.4 (almost neutral Brensted sites usually corresponding to "double" hydroxyls $=\mathrm{Si}(\mathrm{OH})_{2}$ ), and 14.2 (silicon atoms) as shown in Figure 3. The content of other sites including oxygen atoms featuring with a stronger Lewis basicity (centers with $\mathrm{p} K_{\mathrm{a}}-4.4$ and -0.9 ) as well as moderately acidic $\left(\mathrm{p} K_{\mathrm{a}} 2.5\right)$ and basic $\left(\mathrm{p} K_{\mathrm{a}} 8.8\right)$ Brensted centers (hydroxyls) monotonously drops with the increase of the specific surface (Figure 4 ). The exception from this general trend is represented by the strong acidic $\left(\mathrm{p} K_{\mathrm{a}} 0.8\right.$, single hydroxyls) and basic ( $\mathrm{p} K_{\mathrm{a}} 12.8$, likely "triple" hydroxyls$\mathrm{Si}(\mathrm{OH})_{3}$ ) Brensted centers since their content grows with the increase of the specific surface correspondingly up to 100 and $150 \mathrm{~m}^{2} / \mathrm{g}$ (Figure 5). This behavior can be determined by the stabilization of these sites on highly curved surfaces of the smallest nanoparticles.

The content of acidic hydroxyls $\equiv \mathrm{Si}-\mathrm{OH}$ with $\mathrm{p} K_{\mathrm{a}} 0 \cdots 3$ is in a good agreement with IR spectroscopy data on the intensity of absorption band at $3750 \mathrm{~cm}^{-1}$.

The data presented in Figures 3-5 indicate that most of the adsorption centers (particularly with $\mathrm{p} K_{\mathrm{a}}-4.4,-0.9$, $0.8,2.5,6.4$, and 8.8 ) on the surface of Degussa aerosils do not follow the general trends observed for the synthesized materials suggesting significant differences in the surface functionality formation features for these two types of nanosized silica. The comparison of surface functionality profiles between the sample with $S=100 \mathrm{~m}^{2} / \mathrm{g}$ and Degussa Aerosil with a similar specific surface $90 \mathrm{~m}^{2} / \mathrm{g}$ is shown in Figure 6.

The surface of Aerosil A-90 is predominantly occupied by Lewis acidic centers with $\mathrm{p} K_{\mathrm{a}} 14.2$ (silicon atoms or oxygen vacancies), relatively weak Lewis basic centers with $\mathrm{p} K_{\mathrm{a}}-0.3$ (probably corresponding to oxygen atoms in siloxane groups), and strong Brensted acidic groups with $\mathrm{p} K_{\mathrm{a}}$ $0 \cdots 2$ (hydroxyls bound with electron accepting $\mathrm{Si}$ atoms with high Lewis acidity). In contrast, the surface of the synthesized nanosized silica with $S=100 \mathrm{~m}^{2} / \mathrm{g}$ is featured with a significantly higher content of strong Lewis basic centers with $\mathrm{p} K_{\mathrm{a}}-4.5 \cdots-0.9$ (oxygen atoms or silicon 


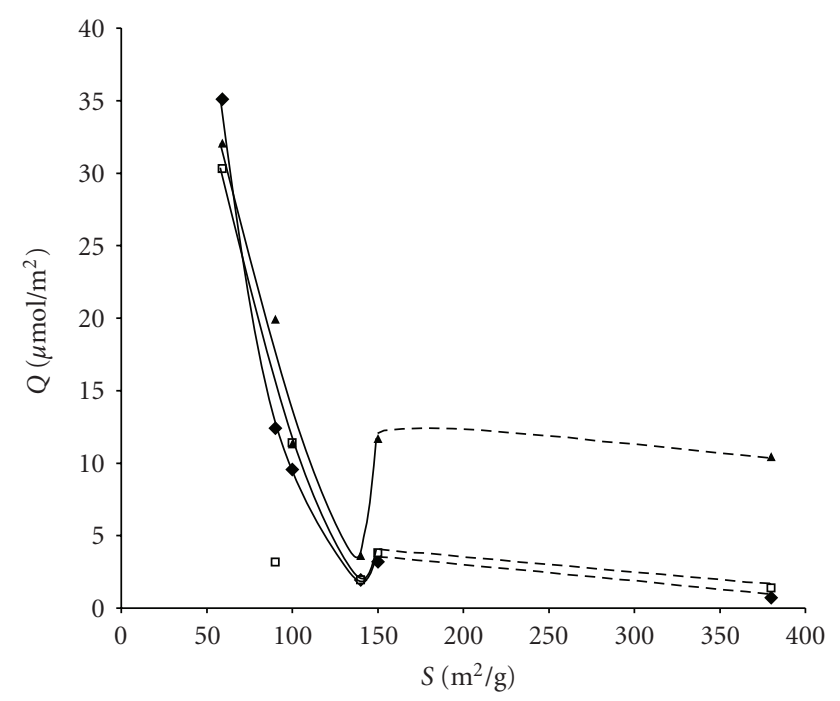

Figure 3: Content of adsorption centers with $\mathrm{p} K_{\mathrm{a}}-0.3(\diamond), 6.4$ (ם), and $14.2(\boldsymbol{\Lambda})$ on the surface of the studied samples as a function of their specific surface area. Note: the content of adsorption centers with $\mathrm{p} K_{\mathrm{a}} 14.2$ is reduced 10 -fold for the presentation convenience.

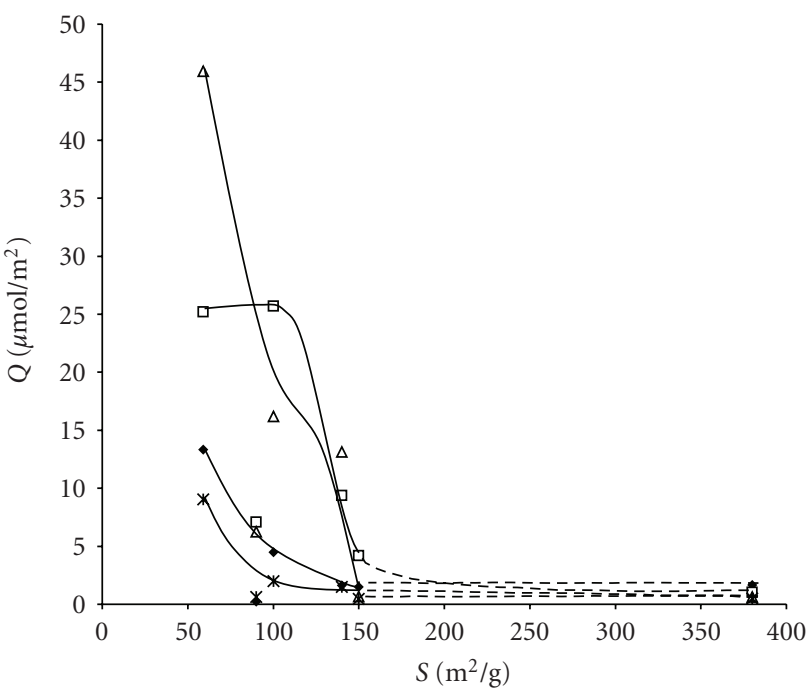

FIgURE 4: Content of adsorption centers with $\mathrm{p} K_{\mathrm{a}}-4.4(\bullet),-0.9$ ( $\square$ ) $2.5(\Delta)$, and $8.8(*)$ on the surface of the studied samples as a function of their specific surface area.

vacancies) as well as Brensted acidic ( $\left.K_{\mathrm{a}} 2.5 \cdots 6.5\right)$ and weakly basic ( $\mathrm{p} K_{\mathrm{a}} 8.8$ ) hydroxyl groups. This unusual surface functionality is probably determined by intensive oxidation processes at electron beam evaporation synthesis leading to a partial destruction of siloxane groups yielding excessive oxygen and hydroxyls on the surface.

\section{Conclusion}

The analysis of nanosized silica powders obtained by electron beam evaporation indicated that the synthesized materials are featured with a reduced apparent density (due to the

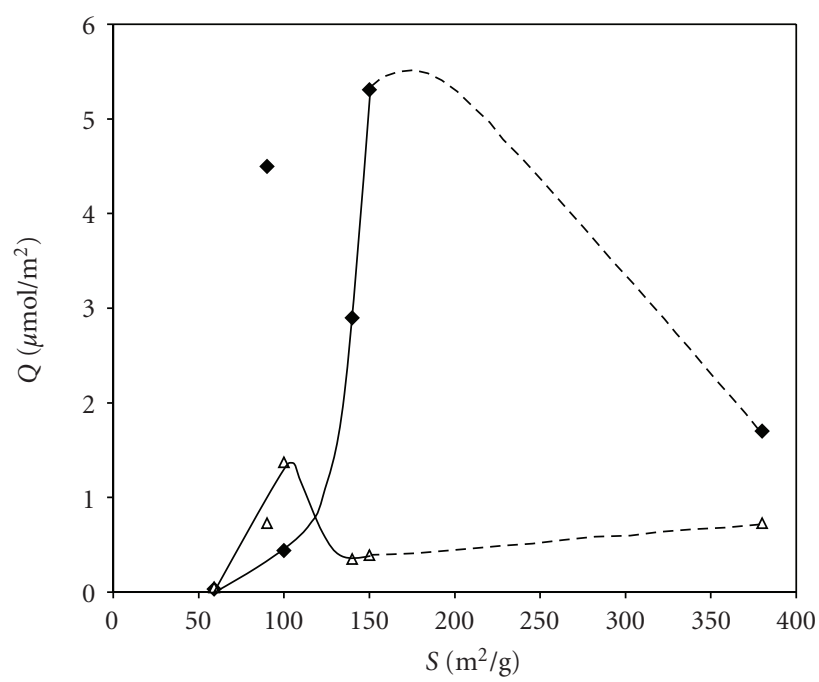

FIgURE 5: Content of adsorption centers with $\mathrm{p} K_{\mathrm{a}} 0.8(\bullet)$ and 12.8 $(\Delta)$ on the surface of the studied samples as a function of their specific surface area.

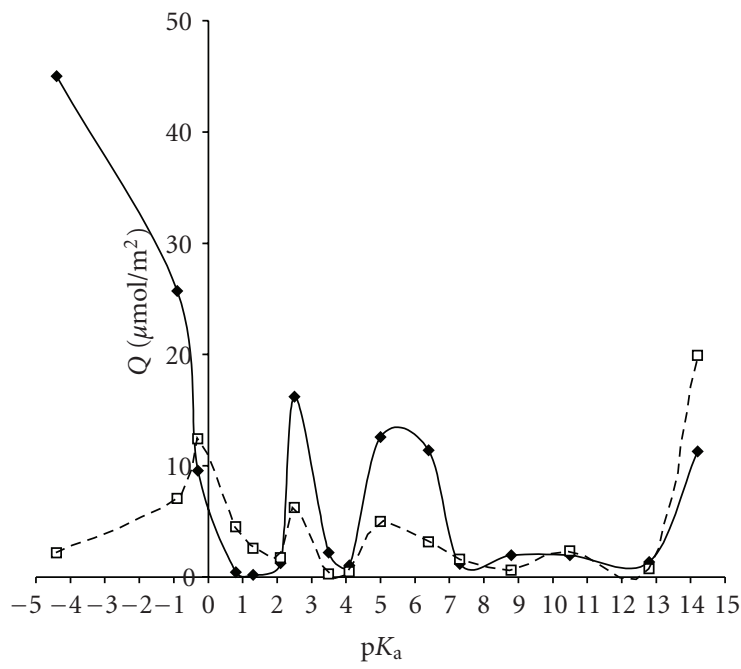

FIGURE 6: Distribution of adsorption centers as a function of their $\mathrm{p} K_{\mathrm{a}}$ values on the surface of electron beam evaporated silica with the specific surface area $S=100 \mathrm{~m}^{2} / \mathrm{g}(\boldsymbol{)})$ in comparison with aerosil A-90 produced by Degussa Co. (ם) Note: the content of adsorption centers with $\mathrm{p} K_{\mathrm{a}} 14.2$ is reduced 10 -fold for the presentation convenience.

porosity or hollows between the particle associates) and increased content of oxygen and hydroxyls on the surface. The considered synthetic method is shown to provide a control over the silica surface functionality by the variation of the process parameters. Electron beam evaporation is generally shown to be a promising approach for the preparation of nanosized silica powders useful as adsorbents for electron accepting compounds (e.g., metal ions) and substrates for the deposition of various layers by reacting with hydroxyl groups. 


\section{Acknowledgment}

The authors are thankful to the Russian Federal Agency of Science and Innovations for a partial financial support of this study under the Contract no. 02.513.12.3099.

\section{References}

[1] R. K. Iler, Chemistry of Silica - Solubility, Polymerization, Colloid and Surface Properties and Biochemistry, John Wiley \& Sons, New York, NY, USA, 1979.

[2] "A way to obtain the ultrafine silica powder, device for its realization and ultrafine silica powder," Russian Patent no. 2067077, 1996.

[3] S. P. Bardakhanov, "The formation of fine silica powder after vaporization of quartz," in Proceedings of the 5th International Conference on Computer Aided Design of Advanced Materials and Technologies (CADAMT '97), pp. 88-89, Baikal Lake, Russia, August 1997.

[4] S. P. Bardakhanov, A. I. Korchagin, N. K. Kuksanov, et al., "Preparation of nanopowders by evaporating initial compounds using electron accelerator at ambient pressure," Doklady Akademii Nauk, vol. 409, pp. 320-323, 2006.

[5] S. P. Bardakhanov, A. I. Korchagin, and N. K. Kuksanov et al., "Nanopowder production based on technology of solid raw substances evaporation by electron beam accelerator," Materials Science and Engineering B, vol. 132, no. 1-2, pp. 204-208, 2006.

[6] I. V. Vasil'eva, S. V. Myakin, E. V. Rylova, and V. G. Korsakov, "Electron-beam modification of the surface of oxide materials $\left(\mathrm{SiO}_{2}\right.$ and $\left.\mathrm{BaTiO}_{3}\right)$," Russian Journal of Physical Chemistry A, vol. 76, no. 1, pp. 71-76, 2002.

[7] S. V. Mjakin, M. M. Sychov, and I. V. Vasiljeva, Eds., Electron Beam Modification of Solids: Mechanisms, Common Features and Promising Applications, Nova Science, Hauppauge, NY, USA, 2009.

[8] A. P. Nechiporenko, Acid-base properties of the surface of solid oxides and chalcogenides, Doctoral thesis, St-Petersburg State Institute of Technology (Technical University), 1995. 

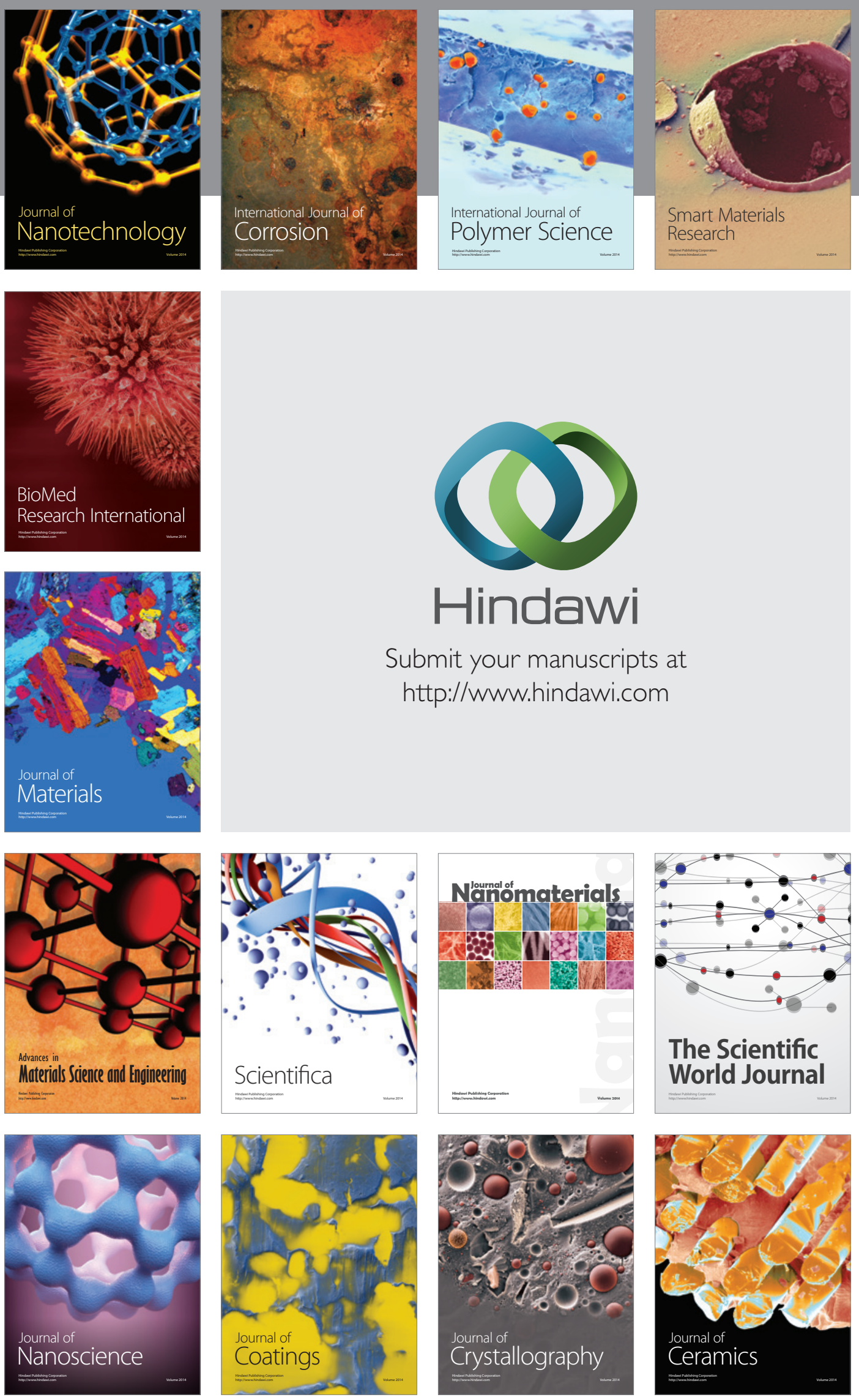

The Scientific World Journal

Submit your manuscripts at

http://www.hindawi.com

\section{World Journal}

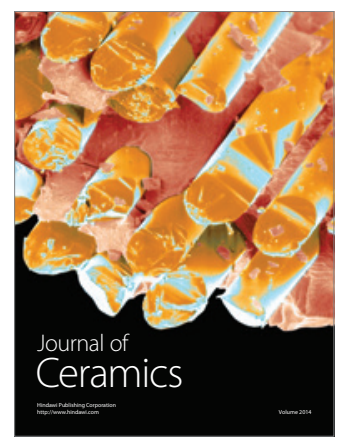

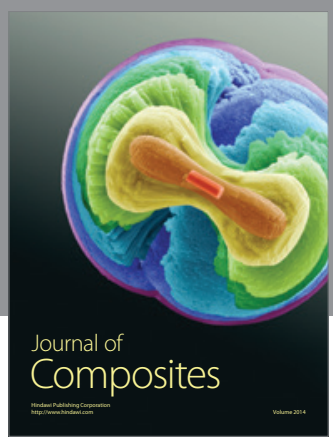
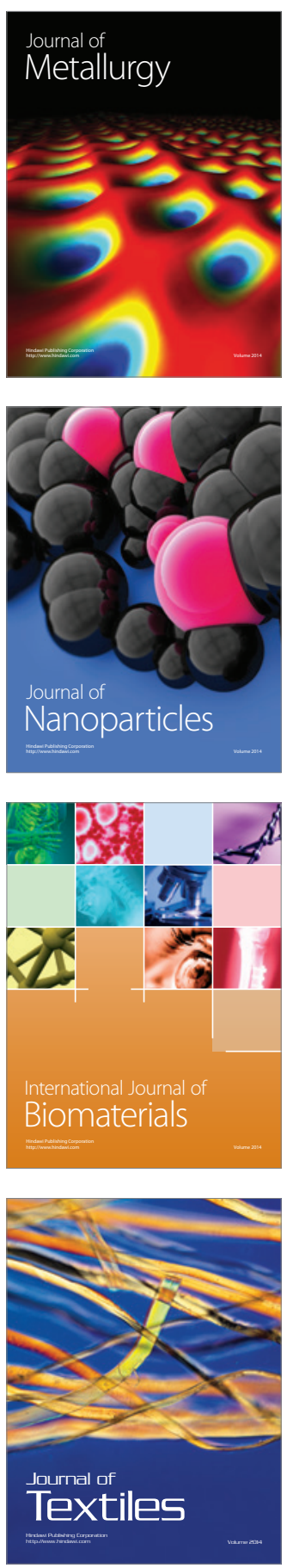